\title{
PRODUÇÃO DE SEDIMENTOS NA REGIÃO METROPOLITANA DE SÃO PAULO. O CASO DA MICROBACIA DO CÓRREGO DO PAU D'ALHO, GUARULHOS, SP
}

\author{
Otacílio de Souza \\ Mestre em Análise Geoambiental - UnG - Colégio COC - Av. Franz Voegeli, 900 - Cep 06020-190 - Osasco-SP - \\ Tel.: (011) 36818000 - e-mail: lioo54@hotmail.com \\ Antonio Manoel dos Santos Oliveira \\ Doutor em Geografia Física - USP - Universidade Garulhos - UnG - Laboratório de Geoprocessamento do Curso de \\ Mestrado em Análise Geoambiental - Praça Tereza Cristina, 229 - Cep 07023-070 - Guarulhos-SP - \\ Tel.: (011) 24641670 - e-mail: aoliveira@prof.ung.br \\ William de Queiroz \\ Especialista em Gestão Ambiental - Universidade Guarulhos - UnG - Laboratório de Geoprocessamento do Curso de \\ Mestrado em Análise Geoambiental - Praça Tereza Cristina, 229 - Cep 07023-070 - Guarulhos-SP - \\ Tel.: (011) 24641670 - e-mail: wqueiroz@ung.br
}

\begin{abstract}
Resumo
O estudo da produção de sedimentos de uma microbacia na periferia urbana de Guarulhos, com base na caracterização dos depósitos tecnogênicos que se formaram no fundo do vale, contribuiu para o conhecimento do processo deflagrado por erosões provocadas pela implantação de um loteamento na Região Metropolitana de São Paulo. Foram reconhecidas as fases de uso do solo, rural e urbana, correlacionadas às produções de sedimentos correspondentes, que atingiram, respectivamente, 120 e $2.320 \mathrm{~m}^{3} / \mathrm{km}^{2}$.ano. A relação de liberação de sedimentos revelou-se muito elevada $(81 \%)$, mostrando a grande eficiência de transferência de sedimentos da microbacia, impactando a jusante o rio Cabuçu de Cima e o rio Tietê, que sempre tem necessitado de custosas obras de desassoreamento.
\end{abstract}

Palavras-chave: produção de sedimentos, depósitos tecnogênicos, Região Metropolitana de São Paulo.

\begin{abstract}
The sediment yield of a micro-watershed, in Guarulhos urban periphery, based on the analysis of a technogenic deposit that occurs in its valley bottom, has contributed to understand this process since erosions deflagrated by the urban expansion of São Paulo Metropolitan Region. This research has recognized a rural and urban land use phases that have produced specific sediment yield of 120 and $2,320 \mathrm{~m}^{3} / \mathrm{km}^{2}$.year, respectively. The estimated $81 \%$ sediment delivery ratio reveals that the microwatershed has a very high potential of sediment transfer to the urban rivers downstream, impacting Cabuçu de Cima and Tietê channels, always submitted to expensive dredging.
\end{abstract}

Keywords: sediment yield, technogenic deposits, São Paulo Metropolitan Region.

\section{Introdução}

A produção de sedimentos das bacias hidrográficas é o principal processo de dinâmica superficial que gera o assoreamento, atualmente um dos problemas geoambientais mais importantes, especialmente em áreas urbanas, onde é responsável por sérios problemas, destacando-se a redução da profundidade de canais, tendo como consequência a perda de eficiência de obras hidráulicas e a produção de cheias frequentes e intensas.

Na Região Metropolitana de São Paulo - RMSP, estes problemas ocorrem de forma intensa assumindo, às vezes, proporções catastróficas quando então são noticiadas na imprensa as inundações de bairros, ruas e avenidas, por trans- 
bordamento de canais de córregos e rios como o Tietê. Tendo em vista o papel do assoreamento na potencialização de tais fenômenos, diversos estudos vem sendo feitos na RMSP, destacando-se os estudos do Instituto de Pesquisas Tecnológicas - IPT e de Centro Tecnológico de Hidráulica CTH (IPT, 1993; Nakazawa; Helou, 1993; Ramos et al., 1993; Ramos, 2002).

Rossini (2005) destaca que, de acordo com o Instituto de Pesquisas Tecnológicas - IPT - e o Departamento de Águas e Energia Elétrica - DAEE , já chegaram a ser retirados da rede hidrográfica natural e construída (calhas da bacia hidrográfica do Alto Tietê, canais, reservatórios, rede urbana de drenagem da RMSP) cerca de 5 milhões de metros cúbicos de sedimento por ano. Segundo Ramos (2002) somente a bacia do Alto Tietê, com cerca de $800 \mathrm{~km}^{2}$, apresenta taxas de assoreamento entre 1.150 .000 e $1.480 .000 \mathrm{~m}^{3} / \mathrm{ano}$, valor que tem a mesma ordem de grandeza dos valores de desassoreamento praticado nesse rio de 1976 a 1989, de $1.100 .000 \mathrm{~m}^{3}$ /ano. Quanto á composição dos sedimentos, o mesmo autor, relata que no rio Tietê foi verificado que 5\% do material é constituído por lixo das mais diferentes formas, mas com um predomínio de restos de materiais de construção. O restante, $95 \%$, é constituído por sedimentos sendo $50 \%$ areia fina, $45 \%$ areia média, $4 \%$ areia grossa e $1 \%$ silteargila.

A persistente produção dos sedimentos que atingem as calhas do rio Tietê e Pinheiros resulta da expansão urbana da RMSP que tem ocorrido de forma inadequada e frequentemente irregular nas periferias. Para Ramos (2002), nas últimas décadas, a RMSP, com 39 municípios e uma área total de $8000 \mathrm{~km}^{2}$, tem passado por um processo de crescimento intenso e desordenado a uma taxa da ordem $20 \mathrm{~km}^{2} /$ ano, atingindo pelo censo de 1991, uma população aproximada de 15 milhões de habitantes distribuída num território que atinge cerca de $1.500 \mathrm{~km}^{2}$ de área urbanizada, do qual cerca de $92 \%$ situa-se dentro da bacia do rio Tietê. Em 2006 a população atingiu 19,7 milhões de habitantes (EMPLASA, 2007).

Campagnoli (2002) destaca que a mancha urbana vem atingindo áreas mais suscetíveis à erosão, onde predominam os terrenos cristalinos, com declividades mais acentuadas e solos rasos. Assim, dependendo da forma de uso do solo, processa-se uma erosão muito intensa, capaz de elevadas taxas de produção de sedimentos. $\mathrm{O}$ autor mostra que os sedimentos produzidos nas microbacias, localizadas no entorno da RMSP, tendem a desembocar em rios de maior porte, como o Cabuçu de Cima em Guarulhos, possibilitando a liberação de sedimentos e o assoreamento dos principais rios da RMSP, como o Tietê.
Entretanto, segundo Santos et al. (2001, apud Maia, 2006) a porcentagem dos sedimentos que atingem os rios e efetivamente são transportados por eles é geralmente pequena em relação às perdas de solo produzidas pela erosão nas bacias. Esta porcentagem depende da área de drenagem e outras características fisiográficas das bacias, além das características hidrodinâmicas dos cursos d'água que transportam os sedimentos.

Além desta lacuna do conhecimento do processo de transferência dos sedimentos desde as áreas fontes erodidas até os cursos d'água, faltam medidas de comportamento de pequenas bacias, em geral não monitoradas. De fato, como observa Campagnoli (2002), Moretti (2001) e Rossini (2005), tanto em área rural quanto urbana, o desafio tem sido a difícil tarefa de calcular as taxas ou volumes de sedimentos produzidos pelas pequenas bacias hidrográficas, pois, em geral, não existem, para este porte de bacia, dados de vazões médias mensais e transporte de sedimentos, de fundo ou em suspensão.

Assim, este artigo visa a apresentar a análise da dinâmica do processo de produção de sedimentos de uma microbacia urbana, com base no estudo de seus depósitos de assoreamento, gerados pela implantação de um loteamento, na RMSP, em Guarulhos, 1986.

Como objetivos específicos decorrentes pode-se apontar: (i) resgatar o histórico do processo de produção de sedimentos, transporte e deposição devido ao uso do solo na microbacia; (ii) caracterizar os depósitos, estimar volumes e taxas de produção de sedimentos; e (iii) caracterizar a situação atual dos processos de erosão e sedimentação na microbacia.

Desta forma, o artigo procura contribuir para o preenchimento das lacunas acima referidas, com o relato de pesquisa sobre depósitos de sedimentos retidos no fundo do vale da microbacia do Pau d'Alho, afluente do rio Cabuçu de Cima, tributário do rio Tietê. Esta pesquisa pertence à linha de pesquisa sobre assoreamento da Geologia de Engenharia, paralela à linha de pesquisa dos estudos hidrossedimentológicos da Engenharia dos Sedimentos, conforme curso de Geologia Aplicada ao Meio Ambiente, do Instituto de Pesquisas Tecnológicas - IPT (Oliveira, 1995) e conferência apresentada no último Simpósio Nacional de Controle de Erosão da Associação Brasileira de Geologia de Engenharia - ABGE (Oliveira, 2009).

\section{Características Físicas da Microbacia}

A área de estudo corresponde à microbacia do córrego Pau d'Alho, contribuinte da bacia hidrográfica do rio Cabuçu de Cima, na bacia do Alto Tietê, localizada no bairro Cabuçu, do município de Guarulhos, ao norte da RMSP, próximo à rodovia Fernão Dias (Figura 1). 


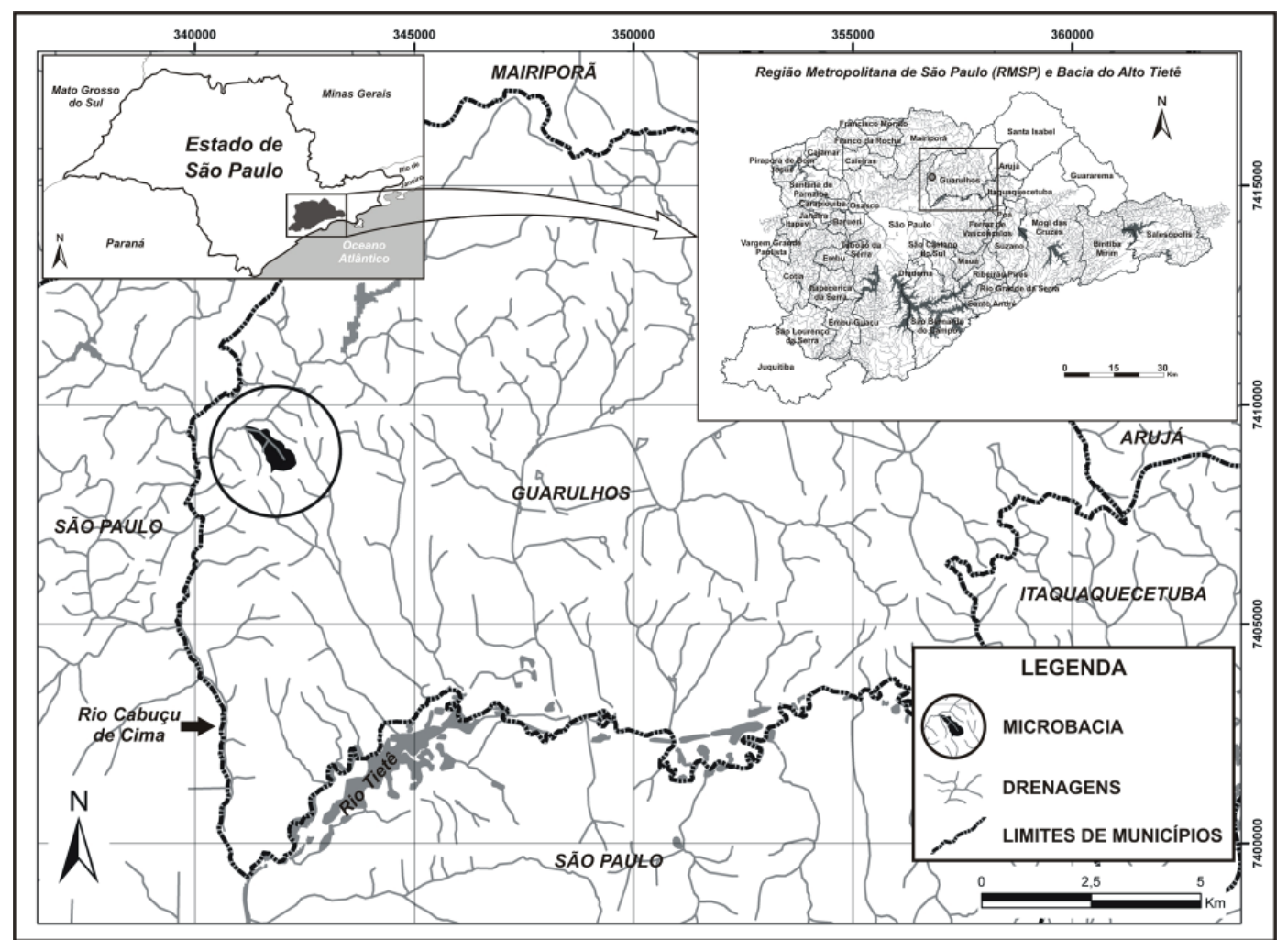

Figura 1: Figura representativa da área de estudo correspondente à microbacia do córrego Pau d'Alho, contribuinte da bacia hidrográfica do rio Cabuçu de Cima, na bacia do Alto Tietê, localizada no bairro Cabuçu, do município de Guarulhos, ao norte da RMSP, próximo à rodovia Fernão Dias

A microbacia situa-se numa zona de transição entre o uso rural e a expansão urbana do município de Guarulhos. A Figura 2 apresenta fotografia aérea da microbacia em 1986, quando foram iniciadas as obras para o loteamento do Parque Continental III que deflagrou a formação do depósito no fundo do vale.

Com cerca de $1450 \mathrm{~m}$ de comprimento, $640 \mathrm{~m}$ de largura máxima, perfazendo um total de $0,51 \mathrm{~km}^{2}$, a microbacia pode ser classificada como de ordem 1 , conforme Strahler (Christofoletti, 1981). O canal apresenta forte entalhamento com largura variável de 1 até $6 \mathrm{~m}$, mostrando em períodos sem chuva, uma lâmina d'água rasa, de 20 a $40 \mathrm{~cm}$, com forte contribuição de esgoto do loteamento Parque Continental III. Entretanto, durante chuvas intensas a lâmina d'água pode crescer até pouco mais de $1 \mathrm{~m}$.

O substrato geológico predominante é constituído por filito de origem metassedimentar, ocorrendo rochas metavulcânicas básicas, associadas a rochas calcosilicáticas na cabeceira da margem direita. Tais litologias constituem a sequência vulcano sedimentar da Formação Morro da Pedra Preta do Grupo Serra de Itaberaba (Juliani, 1993 apud Oliveira et al., 2005). A jusante há uma pequena área de ocor- rência de gnaisse. Associados aos filitos ocorrem latossolos vermelho-amarelos, argilosos, pouco espessos. Associados às metavulcânicas ocorrem latossolos vermelhos, também argilosos, porém mais espessos.

Quanto ao relevo, a região onde se localiza a microbacia encontra-se no denominado Planalto Atlântico, com relevo de morrotes e morros (Ponçano et al.,1981). A microbacia apresenta um desnível de $110 \mathrm{~m}$, entre uma altitude máxima de $860 \mathrm{~m}$ e uma mínima de $750 \mathrm{~m}$, com declividades acentuadas nas vertentes (>30\%) sobretudo próximo ao canal e nas cabeceiras.

\section{Materiais e Métodos}

Para se atingir os objetivos definidos, foi aplicado, como método geral de abordagem, aquele adotado por Oliveira (1994), segundo o qual é realizada a correlação existente entre a história do uso do solo e da formação dos depósitos de assoreamento, denominados tecnogênicos, ou seja, resultantes da ação humana, segundo Chemekov (1982).

Este método é comparável ao de Happ et al. (1940) apud Oliveira (1994) do Serviço de Conservação dos So- 
los - SCS do Departamento de Agricultura Americano (USDA) para medidas de produção de sedimentos em pequenas bacias onde se formaram depósitos nos fundos de vales, devidos à colonização do oeste americano, clas- sificados como "cultural deposits" ou "accelerated valley deposits", denominações equivalentes aos tecnogênicos dos autores russos (Chemekov, 1982; Ter - Stepanian, 1988).

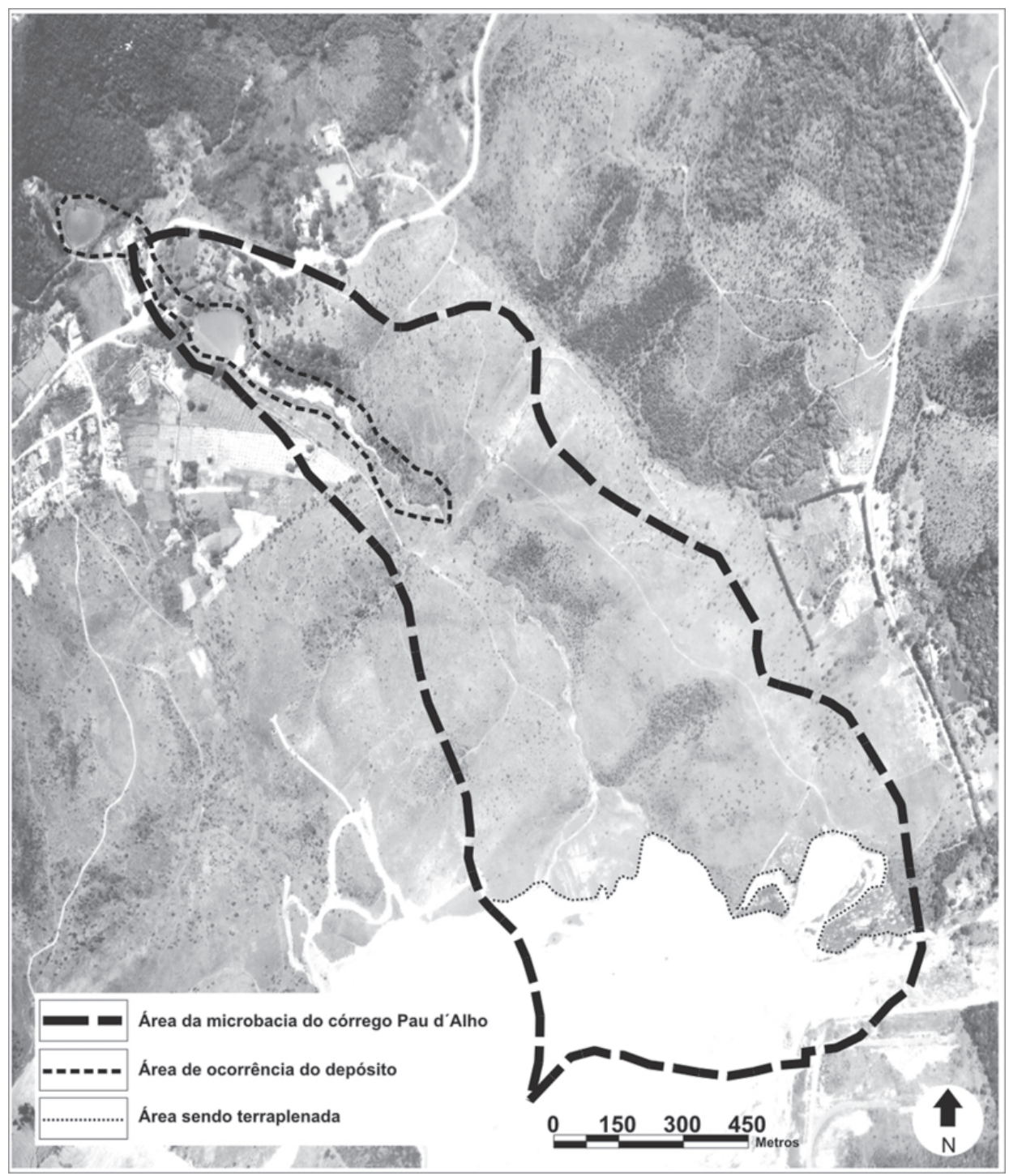

Figura 2: Figura representativa da fotografia aérea da microbacia, área de estudo, em 1986.

Trata-se basicamente de reconhecer as seguintes fases principais:

fase 1: formação do depósito devido ao aporte de sedimentos ser superior à capacidade de transporte do curso d'água, ocorrendo a colmatagem ou assoreamento do fundo do vale.

fase 2: o aporte de sedimentos cessa e o curso d'água recupera sua capacidade de transporte, escavando o depósi- to, entalhando-o de montante para jusante. Em geral, este entalhe é intenso ultrapassando o fundo original do curso d'água, expondo assim o depósito, nos taludes do canal. Este intenso entalhe é provocado pelo aumento da intensidade do escoamento superficial condicionado pela implantação de loteamentos e sua urbanização.

Os volumes envolvidos na fase 1 , até o início da fase 2, durante o período que dura a fase 1 , constituem os elementos 
básicos para o cálculo da produção de sedimento: volumes / tempo.

Para a caracterização do depósito foi realizado um mapeamento de campo da sua ocorrência em superfície, com auxílio de GPS (marca Garmin, modelo GPS 12), com controle em imagem de satélite de alta resolução, Quick-Bird, de 2004. A espessura foi determinada em vários pontos por meio de medidas realizadas através das seções transversais, nos taludes do entalhe do canal e por meio de trado do tipo holandês de 2,5 polegadas. Nas seções, foram escolhidos taludes para a realização de perfis detalhados com análise tátilvisual do material e coleta de amostras.

A análise tátil-visual seguiu as orientações de Pastore; Fontes (1998) e de Pinto (2000), compreendendo a textura, a cor em estado úmido conforme os padrões da "Munsell Soil Colors Chart", a consistência (argilas) e a compacidade (areias) dos solos.

Para a amostragem foi aplicado trado-amostrador, desenvolvido por Souza (2007) de 3,5 polegadas, podendo amostrar até $840 \mathrm{~cm}^{3}$ de material a partir dos taludes do canal do córrego. As amostras foram ensaiadas no Laboratório de Sedimentologia do Centro Tecnológico de Hidráulica -
DAEE/USP, para a determinação da densidade aparente e da granulometria, segundo as Normas da ABNT (1984).

Para resgatar a história do uso do solo foram realizadas interpretações de fotos aéreas de diferentes levantamentos correspondentes aos anos de 1962 (1:25.000, IAC); 1970 (1:20.000, IAC); 1980 (1:35.000, Emplasa); 1986 (1:10.000, Eletropaulo - Sabesp - Emplasa), além da imagem de satélite Quick Bird de 2004, acompanhadas de entrevistas informais com os moradores locais. Ambas atividades foram acompanhadas de observações de campo.

Para a determinação das dimensões das formas erosivas e do entalhe do canal foram realizadas análises da fotografia aérea de 1986 e da imagem de satélite Quick Bird de 2004 e medidas de profundidade e largura das cicatrizes por meio de reconhecimentos de campo.

A Figura 3 apresenta a área de ocorrência do depósito e seu zoneamento em 10 setores para a realização de estudos mais detalhados. A Figura 4 apresenta um exemplo de seção dentre as 10 seções realizadas na área. A Figura 05 apresenta um exemplo de um perfil dentre os 26 perfis realizados na pesquisa.

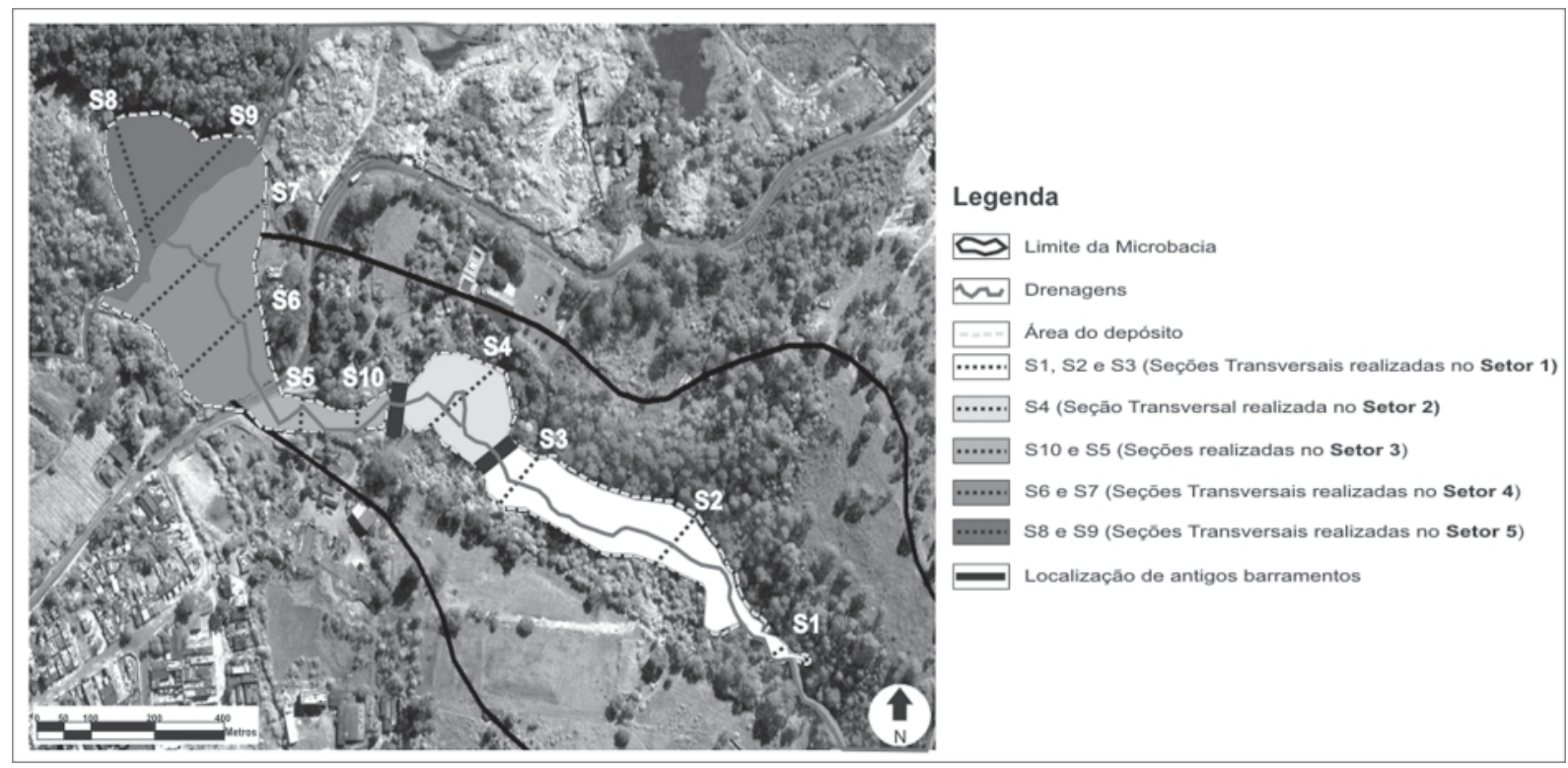

Figura 3: Figura representativa da área de ocorrência do depósito e seu zoneamento em 10 setores para a realização de estudos mais detalhados.

\section{Resultados Obtidos}

Os principais resultados obtidos correspondem ao resgate da história do uso do solo correlacionada à história da formação do depósito, de maneira a se determinar as fases de formação dos depósitos e as taxas correspondentes de produção de sedimentos. Constatou-se que o ano de 1986 pode ser considerado um marco nestas análises, pois foi neste ano que se deu a ruptura com o ambiente rural, provocada pela forma inadequada de implantação do loteamento que deflagrou a intensa produção de sedimentos que colmataram o fundo do vale.

No período anterior, a microbacia foi submetida a um uso rural, apresentando coberturas vegetais que representam atividades econômicas na área: pastagem, reflorestamento e plantação de chuchu, tendo toda a cobertura de mata nativa sido praticamente erradicada até 
1980. O cultivo do chuchu, representando o uso rural mais intenso do solo, embora ocupando apenas $20 \%$ da área da microbacia, foi o principal responsável pela formação de um pequeno depósito tecnogênico rural, de cor bruno-escura, com cerca de $1.500 \mathrm{~m}^{3}$, junto à área cultivada na margem esquerda, que, desenvolvendo-se coluvionarmente, atingiu o fundo vale. Dada a cor e a presença de restos de compostagem de lixo (pedaços de plásticos, tecidos, vidros, etc), este depósito constituiu uma camada guia, entre o substrato geológico e o depósito tecnogênico urbano que o soterrou a partir de 1986. Estimada a duração da plantação em cerca de 24 anos, foi determinada uma taxa de produção de sedimentos, retida no fundo do vale, nesta fase rural, da ordem de 60 $\mathrm{m}^{3} / \mathrm{ano}$, o que equivaleria a uma taxa relativa de quase $120 \mathrm{~m}^{3} / \mathrm{km}^{2}$.ano, em relação à área de toda microbacia.

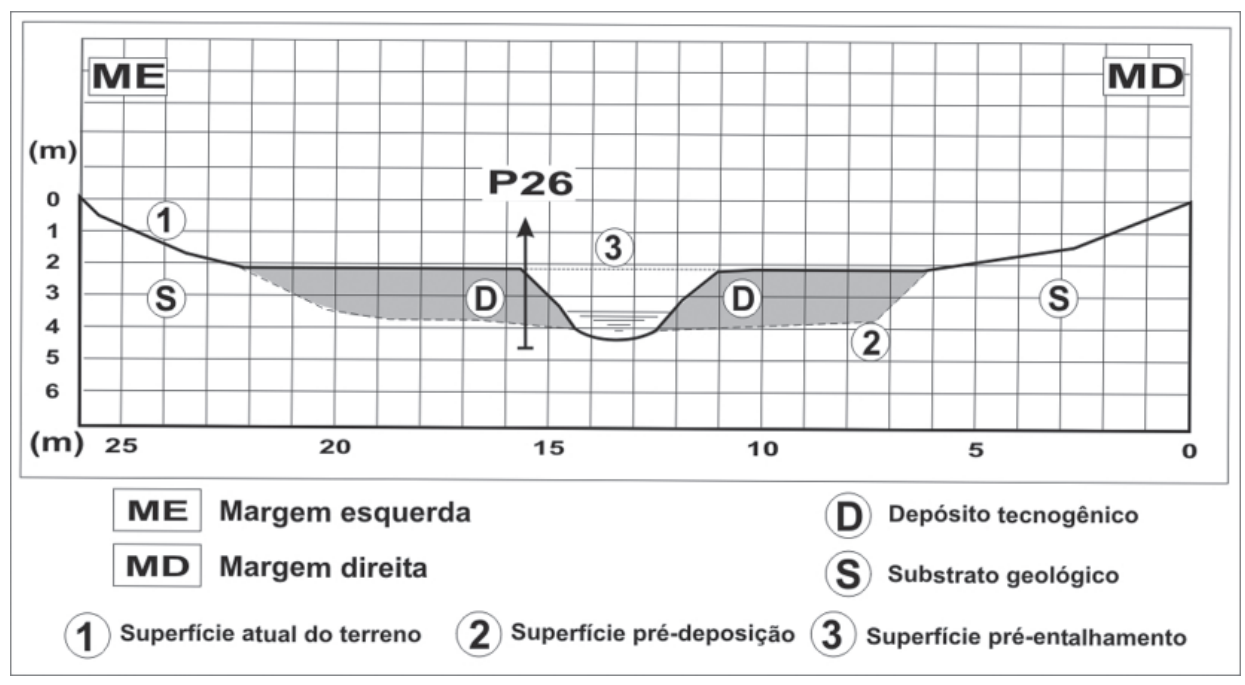

Figura 4: Figura representativa de um exemplo de seção dentre as 10 seções realizadas na área.

\begin{tabular}{|c|c|c|c|c|c|c|}
\hline \multirow{2}{*}{ 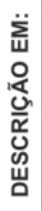 } & \multirow{2}{*}{ 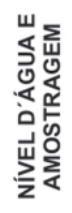 } & \multirow{2}{*}{ 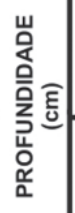 } & \multicolumn{3}{|c|}{$\begin{array}{c}\text { ANÁLISE TÁTIL E VISUAL } \\
\text { (Textura, cor e outras observaçöes) }\end{array}$} & \multirow{2}{*}{ 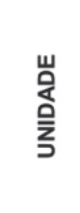 } \\
\hline & & & TEXTURA & $\begin{array}{c}\text { COR } \\
\text { (Tabela Munsell-Soil) }\end{array}$ & OUTRAS OBSERVAÇÕES & \\
\hline \multirow{3}{*}{$\frac{\stackrel{0}{\frac{2}{2}}}{\frac{\pi}{\pi}}$} & \multirow{3}{*}{ A33 } & 65 & Areia & $\begin{array}{c}\text { Cores: } \\
10 \text { YR } 4 / 4 \text { bruno } \\
\text { amarelado escuro } \\
\text { (predomina) } e \\
7,5 \text { YR } 5 \text { / } 6 \text { bruno forte }\end{array}$ & $\begin{array}{l}\text { Camada heterogênea, compacidade } \\
\text { fofa. Sem artefatos, e com raizes. } \\
\text { Superficie coberta com vegetação. } \\
\text { Contato irregular com a camada } \\
\text { inferior. }\end{array}$ & 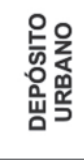 \\
\hline & & 98 & Areia-argilosa & $\begin{array}{c}\text { Cor: } \\
2,5 \text { Y } 4 / 4 \text { bruno oliva }\end{array}$ & $\begin{array}{l}\text { Camada heterogênea, compacidade } \\
\text { média. Sem estratificaçōes. } \\
\text { Com artefatos (tecidos, plásticos e } \\
\text { vidros). Contato irregular com o } \\
\text { substrato. }\end{array}$ & 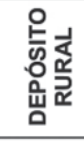 \\
\hline & & 145 & Argila-arenosa & $\begin{array}{c}\text { Cores: } \\
\text { (10 YR 4 / } 6 \text { bruno } \\
\text { amarelado escuro e } \\
\text { 2,5 YR 4 / } 6 \text { vermelho) }\end{array}$ & $\begin{array}{l}\text { Camada heterogênea, consistência } \\
\text { média. Sem estratificaçōes. } \\
\text { Sem artefatos. }\end{array}$ & 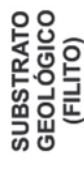 \\
\hline
\end{tabular}

Figura 5: Figura representativa de exemplo de um perfil dentre os 26 perfis realizados na pesquisa. 
A interpretação da foto aérea de 1986 (Figura 2), mostra uma área de solos expostos com marcas de arruamento e ravinas. As principais áreas-fontes dos sedimentos corresponderam à erosão difusa e linear (ravinas) nos aterros. O levantamento da geometria (comprimento, largura e profundidade média) das cicatrizes das erosões, conforme método apresentado, permitiu o cálculo aproximado de um total de $20.678 \mathrm{~m}^{3}$ de materiais erodidos.

Os sedimentos foram sucessivamente formando os depósitos dos setores de 1 a 5 (Figura 3), durante cerca de 4 anos, até o entalhamento do canal.
Nos depósitos predominam silte e areia, sedimentos na sua maior parte oriundos do filito, havendo pouca diferenciação granulométrica entre os setores estudados. A densidade aparente média dos sedimentos é de cerca $1,5 \mathrm{t} / \mathrm{m}^{3}$, valor que permite determinar os índices de produção de sedimentos em volume $\left(\mathrm{m}^{3}\right)$ ou massa $(\mathrm{t})$, conforme abordagem dos estudos hidrossedimentológicos (Carvalho, 1994). A tabela 1 apresenta as principais características das unidades pesquisadas.

Tabela 1: Principais características das unidades pesquisadas.

\begin{tabular}{|c|c|c|c|c|}
\hline Caracterísitcas & $\begin{array}{c}\text { Aterro } \\
\text { (Fonte de sedimentos) }\end{array}$ & Depósito Urbano & Depósito Rural & $\begin{array}{c}\text { Substrato } \\
\text { (rocha alterada) }\end{array}$ \\
\hline Ocorrência & $\begin{array}{l}\text { Grandes volumes } \\
\text { depositados a meia } \\
\text { encosta, muito } \\
\text { erodidos (ravinas) }\end{array}$ & $\begin{array}{c}\text { Fundo do vale como aluvião } \\
\text { e assoreamento de } \\
\text { reservatórios }\end{array}$ & $\begin{array}{c}\text { Fundo do vale, como } \\
\text { coluvião sob o depósito } \\
\text { urbano }\end{array}$ & $\begin{array}{l}\text { Fundo do vale, sob os } \\
\text { depósitos tecnogênicos }\end{array}$ \\
\hline Textura & Silto-areno-argiloso & Areno-silto-argiloso & Areno-silto-argiloso & $\begin{array}{l}\text { De filito: argilo-areno-siltoso } \\
\text { De granito: areno-silto-argiloso. }\end{array}$ \\
\hline Cor & $\begin{array}{c}\text { Bruno escuro } \\
(7,5 \text { YR 4/4) }\end{array}$ & $\begin{array}{l}\text { Bruno escuro } \\
(7,5 \text { YR } 4 / 4)\end{array}$ & $\begin{array}{l}\text { Bruno amarelado escuro } \\
\qquad(10 \text { YR } 3 / 4)\end{array}$ & $\begin{array}{c}\text { Bruno amarelado escuro } \\
\text { (10 YR 4/6) e Cinza claro } \\
(10 \text { YR } 7 / 1)\end{array}$ \\
\hline $\begin{array}{c}\text { Densidade } \\
\text { natural média } \\
\text { aproximada }\left(\mathrm{t} / \mathrm{m}^{3}\right)\end{array}$ & 1,4 & 1,5 & 1,5 & 1,6 \\
\hline $\begin{array}{l}\text { Compacidade } \\
\text { (quando mais } \\
\text { arenosa) }\end{array}$ & Fofa & Fofa e média & Fofa & Média \\
\hline $\begin{array}{l}\text { Consistência } \\
\text { (quando mais } \\
\text { argilosa) }\end{array}$ & Média e Rija & Média e Rija & Média e Rija & Média e Rija \\
\hline $\begin{array}{c}\text { Outras } \\
\text { observações }\end{array}$ & $\begin{array}{l}\text { Material heterogêneo. } \\
\text { Sem artefatos. }\end{array}$ & $\begin{array}{l}\text { Camadas homogêneas e } \\
\text { heterogêneas com estra- } \\
\text { tificações centimétricas }\end{array}$ & $\begin{array}{l}\text { Camadas homogêneas. } \\
\text { Sem estratificações. } \\
\text { Com artefatos (cerâmicas, } \\
\text { plásticos, vidros, etc.) }\end{array}$ & $\begin{array}{l}\text { Camadas homogêneas. } \\
\text { Sem estratificações. } \\
\text { Sem artefatos }\end{array}$ \\
\hline
\end{tabular}

Após a deposição dos sedimentos seguiu-se a fase de entalhamento do canal. Durante a pesquisa o volume deste canal, estimado com o mesmo procedimento do levantamento das cicatrizes de erosão, era de $8.610 \mathrm{~m}^{3}$. O volume da erosão nas áreas fontes, $\left(20.678 \mathrm{~m}^{3}\right)$ somado ao volume correspondente ao entalhe do canal $\left(8.610 \mathrm{~m}^{3}\right)$ atingiu 29.288 $\mathrm{m}^{3}$, correspondente ao total de sedimentos produzidos pela microbacia. O volume retido no fundo do vale, após o entalhamento foi estimado em $5.593 \mathrm{~m}^{3}$. Os sedimentos restantes (volume de $23.695 \mathrm{~m}^{3}$ ) liberados pela microbacia, implicam numa taxa de produção, ao longo dos últimos 20 anos, de $1.185 \mathrm{~m}^{3} /$ ano que, em relação à área da bacia, corresponde a uma produção específica de $2.320 \mathrm{~m}^{3} / \mathrm{km}^{2}$ ano $(3.480 \mathrm{t} /$ $\mathrm{km}^{2}$.ano). A tabela 2 resume as estimativas da produção de sedimento.

\section{Conclusões}

O estudo do processo de urbanização da microbacia do Pau d' Alho, afluente do rio Cabuçu de Cima, em Guarulhos, SP, constitui um exemplo de caracterização da dinâmica da produção de sedimentos com base na ocorrência de depósitos tecnogênicos (Oliveira, 1994). Esta dinâmica, que acompanha o uso do solo da microbacia desde sua fase rural, está ilustrada na Figura 6 (Souza, 2007). 
Tabela 2: Estimativas da produção de sedimentos.

\begin{tabular}{|c|c|c|c|c|c|c|}
\hline & \multirow[b]{2}{*}{$\begin{array}{c}\text { Fase } \\
\text { (tempo) }\end{array}$} & \multicolumn{2}{|c|}{ Produção Retida } & \multicolumn{2}{|c|}{ Produção Liberada } & \multirow[b]{2}{*}{$\begin{array}{r}\text { RLS } \\
(\%)\end{array}$} \\
\hline & & $\begin{array}{c}\text { Bruta } \\
\mathrm{m}^{3} / \text { ano } \\
\text { (t/ano) }\end{array}$ & $\begin{array}{l}\text { Específica } \\
\mathrm{m}^{3 /} / \mathbf{k m}^{2} \text { ano } \\
\left(\mathrm{t} / \mathrm{km}^{2} \text { ano) }\right.\end{array}$ & $\begin{array}{c}\text { Bruta } \\
\mathrm{m}^{3} / \text { ano } \\
\text { (t/ano) }\end{array}$ & 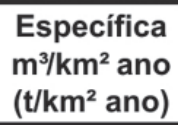 & \\
\hline & Rural & 61 & 120 & & & \\
\hline & (24 anos) & (91) & (180) & -- & -- & -- \\
\hline \multirow{6}{*}{$\begin{array}{l}\text { 옳 } \\
\text { 은 } \\
\text { 늘 }\end{array}$} & Setor 1 & 2.745 & 5.382 & & & \\
\hline & (1 ano) & $(4.120)$ & $(8.080)$ & -- & -- & -- \\
\hline & Todos setores & 1.400 & 2.800 & & & \\
\hline & (4 anos) & $(2.100)$ & $(4.200)$ & -- & -- & -- \\
\hline & Todos setores & 279 & 547 & 1.185 & 2.320 & \\
\hline & (20 anos) & (419) & (820) & (1.777) & (3.484) & 81 \\
\hline
\end{tabular}

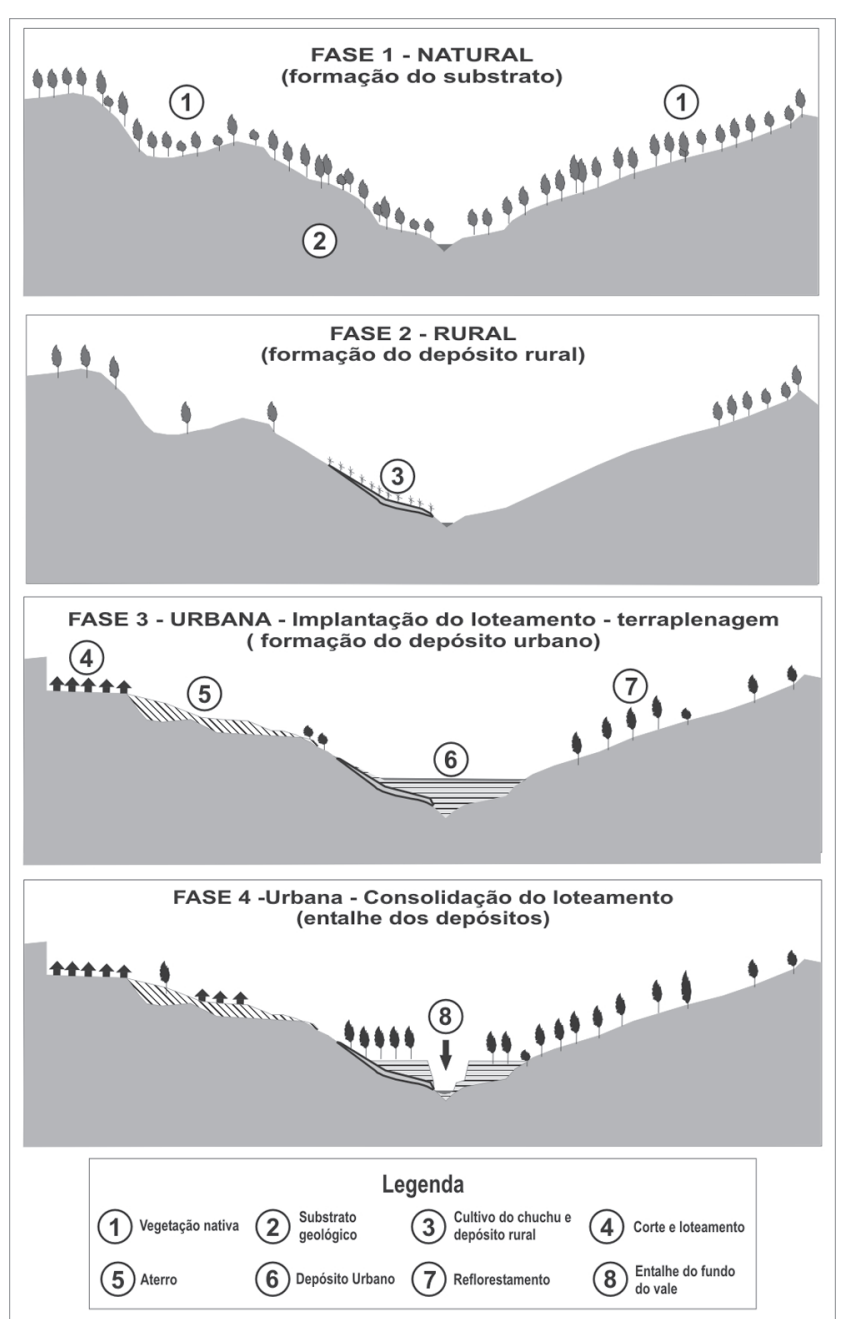

Figura 6
O estudo mostrou como se dá o processo de produção de sedimentos em microbacia, como um exemplo do que está sucedendo com a expansão urbana da Região Metropolitana de São Paulo. Desta forma, a pesquisa contribui para relacionar as duas pontas dos estudos que vem sendo realizados na RMSP, da erosão ao assoreamento. Os valores de taxas de produção de sedimentos podem ser considerados compatíveis com aqueles apresentados por diversos autores em trabalhos similares onde se destacam, para pequenas bacias em processo de urbanização, produções de sedimentos da ordem de milhares de toneladas por ano e por $\mathrm{km}^{2}$.

Verificou-se que houve pequena retenção de sedimentos no fundo do vale o que se manifesta numa relação de liberação de sedimentos bastante elevada (81\%), entre o que foi exportado pela bacia e o total do que foi erodido. Este valor é esperado para bacias de pequeno porte conforme a UNESCO (CARVALHO, 1994) que aponta, numa síntese para várias bacias do mundo, valores dessa relação de 50 a quase $100 \%$ para bacias com áreas semelhantes. Este diagnóstico confirma o alerta de vários autores para o aumento da produção de sedimentos para a calha do rio Tietê à medida que a área urbana se expande para regiões de relevo mais acentuado e maior suscetibilidade à erosão da RMSP.

O entalhamento do depósito do fundo da microbacia e a ocupação irregular das cabeceiras continuam, promovendo a produção de sedimentos e consequentes danos sócio ambientais, tanto na própria microbacia, como no rio Cabuçu de Cima, cujo canal encontra-se atualmente extremamente assoreado, e no rio Tietê, cujos problemas de inundação e de serviços de desassoreamento prosseguirão, enquanto se multiplicam os processos erosivos na expansão da RMSP. 


\section{Agradecimentos}

Os autores agradecem ao Sr. Tadeu Laet e família pelo apoio à pesquisa realizada nos terrenos de sua propriedade. Agradecem também à colaboração do Geógrafo Weber da Costa Lourenço nos trabalhos de campo. E ainda, à Engenheira Dra. Elizabeth Amádio, Técnico em Agronomia Wagner Curis Junior (Centro Tecnológico de Hidráulica - CTH) e à Bióloga Andréa Barbieri (Universidade Guarulhos - UnG), pelas análises granulométricas realizadas nos respectivos laboratórios do CTH e UnG.

\section{Referências Bibliográficas}

ASSOCIAÇÃO BRASILEIRA DE NORMAS TÉCNICAS ABNT. NBR 7181: solo: análise granulométrica. Rio de Janeiro, 1984.

CAMPAGNOLI, F. A. Aplicação do assoreamento na definição de geoindicadores ambientais em áreas urbanas do Alto Tietê. 2002. 192 f. Tese (Doutorado em Engenharia Hidráulica) - Escola Politécnica, Universidade de São Paulo, São Paulo, 2002.

CARVALHO, N.O. - 1994 - Hidrossedimentologia prática. Rio de Janeiro : CPRM - Companhia de Pesquisa em Recursos Minerais. 372 p.

CHEMEKOV, Y. F. Technogenic deposits. In: INQUA CONGRESS, 11, 1982. Moscou: Abstracts, v. 3, $62 \mathrm{p}$.

CHRISTOFOLETTI, A. Geomorfologia fluvial. São Paulo: Edgard Blucher, 1981. 313 p.

EMPLASA-EMPRESAPAULISTA DE PLANEJAMENTO METROPOLITANO S/A. Disponível em: < http:/ /www.emplasa.sp.gov.br > Acesso em: 18 jun. 2007

INSTITUTO DE PESQUISAS TECNOLÓGICAS DO ESTADO DE SÃO PAULO - IPT. Erosão $e$ assoreamento nas bacias dos rios Tietê e Pinheiros: diagnóstico e diretrizes para a solução integrada do problema. São Paulo: IPT, 1993. 61 p. v. 19. (Relatório IPT, 30.796).

MAIA, A. G. As consequências do assoreamento na operação de reservatórios formados por barragens, 2006. 163 f. Tese (Doutorado em Engenharia Hidráulica) - Escola de Engenharia de São Carlos, 2006.

MORETTI, L. R. Avaliação da erosão em pequenas bacias hidrográficas rurais. São Paulo. 2001. 128 f. Tese (Doutorado em Engenharia Hidráulica) - Escola
Politécnica, Universidade de São Paulo, São Paulo, 2001.

NAKAZAWA, V. A.; HELOU, G. C. N. Erosão nas bacias dos rios Tietê e Pinheiros: aspectos físicos e antrópicos. In: SIMPÓSIO BRASILEIRO DE RECURSOS HÍDRICOS, 10.; SIMPÓSIO DE RECURSOS HÍDRICOS DO CONE SUL, 1. 1993, Gramado. Anais... Gramado: ABRH, 1993. v. 5 , p. $464-273$.

OLIVEIRA, A. M. S. Depósitos tecnogênicos e assoreamento de reservatórios: exemplo do reservatório de Capivara, Rio Paranapanema, SP/PR. 1994, 211 f. Tese (Doutorado em Geografia Física) Faculdade de Filosofia, Letras e Ciências Humanas, Universidade de São Paulo, São Paulo, 1994.

OLIVEIRA, A. M. S. Assoreamento em cursos e corpos d'água. In Bitar (coord.) 1995. Curso de Geologia Aplicada ao Meio Ambiente. São Paulo: ABGE; IPT. P. 59 - 76.

OLIVEIRA, A. M. S. et al. Diagnóstico ambiental para o manejo sustentável do núcleo Cabuçu do Parque Estadual da Cantareira e áreas vizinhas do município de Guarulhos. Guarulhos: Universidade Guarulhos, 2005. Projeto Cabuçu UnG/Fapesp. p. 54-66.

OLIVEIRA, A. M. S. O Papel da Geologia de Engenharia no estudo do assoreamento. In: SIMPÓSIO BRASILEIRO DE CONTROLE DE EROSÃO, 8. , 2009. Anais... São Paulo: ABGE, 2009. CD-ROM.

PASTORE, E. L.; FONTES, R. M. Caracterização e classificação de solos. In: OLIVEIRA, A. M. S.; BRITO, S. N. A. (Ed.) Geologia de engenharia. São Paulo: ABGE, 1998. p. 197-210.

PINTO, C. S. Curso básico de mecânica dos solos. São Paulo: Oficina de Textos, 2000. 247 p.

PONÇANO, W. et al., Mapa Geomorfológico do Estado de São Paulo-Escala 1:1.000.000.. São Paulo: IPT - Instituto de Pesquisas Tecnológicas do Estado de São Paulo. Publicação 1183, Monografia 5, 130 p. 1981.

RAMOS, C. L. Transporte de sedimentos nos rios da Região Metropolitana de São Paulo. In: ENCONTRO NACIONAL DE ENGENHARIA DE SEDIMENTOS, 5., 2002, São Paulo. Anais... São Paulo: ABGE, 2002. p. 3-6.

ROSSINI, J. C. C. Estudo da relação de vazão sólida x vazão líquida em pequenas bacias urbanas. São Paulo. 2005. 160 f. Dissertação (Mestrado em Engenharia 
Hidráulica) - Escola Politécnica, Departamento de Engenharia Hidráulica e Sanitária, Universidade de São Paulo, 2005.

SOUZA, O. Produção de sedimentos em áreas urbanas. O caso da microbacia do córrego do Pau d'Alho, Guarulhos. SP. Dissertação de mestrado.
Guarulhos: Mestrado em Análise Geoambiental. 2007. 75 p. Anexos.

TER-STEPANIAN, G. Beginning of the Technogene. Bulletin of the International Association of Engineering Geology. (38): 133-142. 1988. 